\begin{tabular}{l|c|c}
\hline \hline Vol. 26(2):219-230 & Ocean and Polar Research & June 2004 \\
\hline \hline
\end{tabular}

\title{
Article
}

\section{Relationship Between Manganese Nodule Abundance and Geologic/Topographic Factors of the Southern KODOS Area in the Northeastern Equatorial Pacific Using GIS and Probability Method}

\author{
Young-Tak Ko ${ }^{1 *}$, Kyung-Duck Min $^{2}$, Cheong-Kee Park ${ }^{1}$, Jung-Keuk Kang ${ }^{1}$, \\ Ki-Hyune Kim ${ }^{1}$, Tae-Gook Lee ${ }^{1}$, and Hyun-Sub Kim ${ }^{1}$ \\ ${ }^{1}$ Marine Geoenvironment and Resources Research Division, KORDI \\ Ansan P.O. Box 29, Seoul 425-600, Korea \\ ${ }^{2}$ Department of Earth System Sciences, Yonsei University \\ Seoul 120-749, Korea
}

\begin{abstract}
The aims of this study are to construct database using geostatistics and Geographic Information System (GIS), and to derive the spatial relationships between manganese nodule abundance and each factor affecting nodule abundance, such as metal grade, slope, aspect, water depth, topography, and acoustic characteristics of the subbottom using the GIS and probability methods. The greater is the copper and nickel grade, the higher is the rating. The distribution pattern of nickel grade is similar to that of copper grade. The slopes are generally less than $3^{\circ}$, excluding seamounts and cliff areas. There is no increment in the rating with increasing slope. The rating is highest for slopes between 2.5 and $3.5^{\circ}$ in block B2 and between 3 and $6^{\circ}$ in block $\mathrm{C} 1$. The topography is classified into five groups: seamount, hill crest, hill slant, hill base or plain, and seafloor basin or valley. The ratings prove lowest for seamount and hill crest. The results of the study show a decrease in the rating with an increase in water depth in the study area. There was a poor relationship between manganese nodule abundance and the thickness of the upper transparent layer in block C1. Using GIS, it is possible to analyze a large amount of data efficiently, and to maximize the practical application, to increase specialization, and to enhance the accuracy of the analyses.
\end{abstract}

Key words : Manganese nodule, Geographic Information System (GIS), Probability, Rating

\section{Introduction}

The submarine ferromanganese concretion was first discovered in the Kara Sea of Russia in 1868 (Earney 1990). In the course of its round-the-world expedition from 1873 to 1876 , HMS Challenger collected many small dark-brown balls, rich in manganese and iron, which were named manganese nodules (Manheim 1978; Earney 1990). Since the 1960s, manganese nodules have been recognized as a potential source of nickel, copper, cobalt, and manganese, due to the progressive depletion of land-based mineral resources. Manganese nodules are found on the seabed in

*Corresponding author. E-mail : ytko@kordi.re.kr many areas, and have been comparatively well studied for their distribution because of their potential economic importance. These nodules are most abundant in the ClarionClipperton Fracture Zone (C-C zone). Because of this, the $\mathrm{C}-\mathrm{C}$ zone has been the focus of much international attention (Mero 1965; Frazer 1979; McKelvey et al. 1979; Bernhard and Blissenbach 1988).

The ultimate purpose of the study for manganese nodules is to find nodule deposits that are economically feasible for commercial development. The selection of manganese nodule deposits has been determined by geological and economic criteria provided by specialists. France fixed the criteria for manganese nodule deposits in terms of nodule abundance $\left(>5 \mathrm{~kg} / \mathrm{m}^{2}\right)$, metal grade $(\mathrm{Cu}+\mathrm{Ni}>2.5 \%)$, slope 
of the seabed $\left(<10^{\circ}\right)$, spatial continuity of nodule deposits (the absence of nodules $<1,000 \mathrm{~m}$ ), and the height of the escarpment (<1 m) (IFREMER 1989). Korea also set criteria similar to France, but more specific cutoff grades for $\mathrm{Cu}\left(>1.03 \%\right.$ or $\left.50 \mathrm{~g} / \mathrm{m}^{2}\right)$ and $\mathrm{Ni}\left(1.24 \%\right.$ or $\left.60 \mathrm{~g} / \mathrm{m}^{2}\right)$ (MOMAF 1997, 1999).

Recently, a geographic information system (GIS) was adopted for deep-sea resources data such as manganese nodules or crusts with advances in computer technology. Using GIS, it is possible to analyze large amounts of data with increased efficiency, and to maximize the management of practical applications. The use of probability and statistical methods allows for more specialized studies and enhances the accuracy of the analysis. For these advantages, GIS and probability methods were used for suitable site investigation of manganese nodules. However, the use of GIS in the deepsea resource field has been limited to the construction of database (JICA and MMAJ 2000) and rating and weighting of past studies on a partial block of the KODOS area (Ko 1997).

The objectives of this study are to construct a database using geostatistics and GIS, and to derive the spatial relationships between nodule abundance and each factor affecting nodule abundance, such as metal grade, slope, aspect, water depth, topography, and acoustic characteristics of the subbottom using the GIS and probability methods. The probability and statistical methods were newly adopted for the study area. The rating was quantified by applying probability methods to a database and development potential maps produced by means of GIS.

Using the nodule abundance obtained from sampling data together with a spatial database, two analytical methods were applied. The rating was calculated by analyzing the correlation between nodule abundance and the metal grade, slope, aspect, water depth, topography, and acoustic characteristics of the subbottom. By combining GIS with probability methods, the relationships and contrast values between nodule abundance and each factor affecting abundance were assessed.

The study area is located in the central part of the C-C zone, in the northeastern Pacific. It lies between 9 and 12N latitude, and 128 and 133W longitude (Fig. 1). The study area is composed of 2 blocks, B2 and $\mathrm{C} 1$, which is the area designated for Korea. The water depth of the study area ranges from 4,394 $\mathrm{m}$ to $5,666 \mathrm{~m}$. The seafloor of the study area is generally deeper than $4,800 \mathrm{~m}$, and slopes gently toward the northwest. The seafloor is older toward the northwest and largely offset by a fracture zone which is indistinct in the general bathymetric trend. The

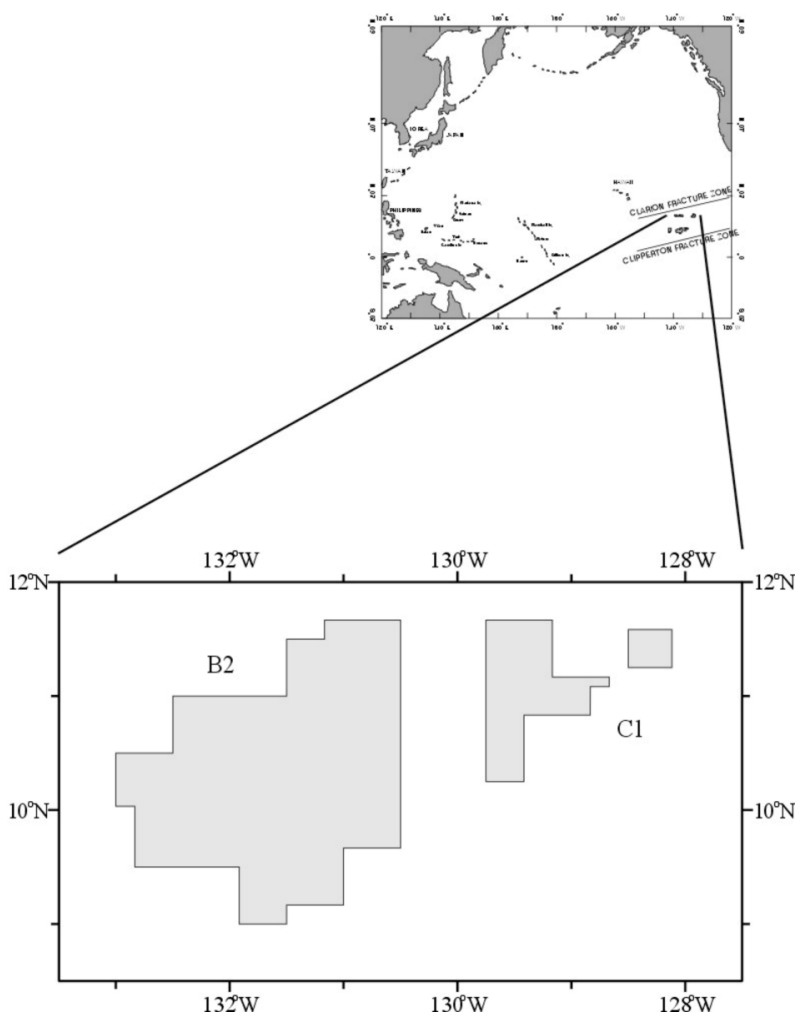

Fig. 1. Location of study area in the northeastern equatorial Pacific.

seamounts are mostly steep-sloped, wide ( 5 to $30 \mathrm{~km}$ ) and high (400 to $1,500 \mathrm{~m}$ ), aligned in an E-W trend. They form ridges, following the general bathymetric pattern in the $\mathrm{C}-\mathrm{C}$ zone. They lack sediments on the peaks and slopes, but are often covered with a thick sediment layer and are complicated with irregular block and step faults. The seafloor basement is also irregular, dissected by numerous faults, especially in the eastern part that forms a small and large subdued basin floor covered with a thin sediment layer.

\section{Materials and methods}

\section{Manganese nodule abundance}

Sampling and abundance measurement of manganese nodules were performed to understand their distribution pattern in the study area, and to obtain the basic data for estimation and evaluation of metal grade using geostatistical methods. The nodule's abundance was determined by collecting nodules from a small area of the seafloor using a Free Fall Grab (FFG). The photographs of the sea bottom were obtained by a camera attached to the sampler which was used to correct nodule abundance data whose estimates were based on nodule samples collected by FFG. 
The nodule's abundance was defined as the nodule's weight collected by the FFG per unit area $\left(\mathrm{kg} / \mathrm{m}^{2}\right)$, which could be expressed by the following equation:

$$
A b .=\frac{W i}{S}
$$

where $A b$. is the nodule's abundance $\left(\mathrm{kg} / \mathrm{m}^{2}\right), W i$ is the weight of collected nodules $(\mathrm{kg})$ and $S$ is the collection area of FFG $\left(\mathrm{m}^{2}\right)$.

The collected abundance of manganese nodules should be subjected to revision before applying it to the coverage of the nodules' population and abundance, because the collected nodule amount is lower due to the collection efficiency of grabs less than 1 . The abundance of manganese nodules $(A b$. $)$ was corrected by multiplying the correction constant of 1.29 (MOMAF 1996) which was determined from the comparison with photo data acquired from the past cruises. The correction constant of 1.29 is similar to the suggested value attained by the experimental method of the Ocean Minerals Company (OMCO 1992).

$$
Y=1.29 \times A b .
$$

where $Y$ is the nodule's corrected abundance, $A b$. is the sample abundance and 1.29 is the correction constant.

The collected manganese nodules were analyzed for major and minor elemental concentrations using an Inductively Coupled Plasma Atomic Emission Spectrometer (ICP-AES). Sampling data includes position, depth of the sampling site, abundance of nodules (in wet $\mathrm{kg} / \mathrm{m}^{2}$ ) and contents of manganese, nickel, copper, cobalt, and other metals in terms of the percentage of dry weight. All of this collected data is essential in terms of analyzing the resource distribution along the seafloor. The data analyses for copper and nickel grade were carried out using GIS to establish the relationship between the metal grade and nodule abundance.

The grade of useful metals was obtained by multiplying manganese nodule abundance $\left(\mathrm{kg} / \mathrm{m}^{2}\right)$ to metal content (\%). The units of the metal grade is defined by the weight per unit area $\left(\mathrm{g} / \mathrm{m}^{2}\right)$. The cutoff grade of abundance was fixed at $5 \mathrm{~kg} / \mathrm{m}^{2}$. The cutoff grade of copper is $1.03 \%$ or $50 \mathrm{~g} / \mathrm{m}^{2}$, and the cutoff grade of nickel is $1.24 \%$ or $60 \mathrm{~g} /$ $\mathrm{m}^{2}$ (Archer 1976; Holser 1976; Kildow et al. 1976; Frazer 1977; Park 1995).

The analyses for copper and nickel grade were carried out using Spatial Analyst and 3D Analyst module of ARC/INFO to establish the relationship between metal grade and nodule abundance. The grade of copper and nickel is represented by a gram per unit area $\left(\mathrm{g} / \mathrm{m}^{2}\right)$. It is classified into 18 and 23 groups at a 10 gram interval.

\section{Multibeam echo sounding data}

Swath bathymetric data was obtained to evaluate the geomorphic and topographical features of the study area using a SeaBeam 2000 and Sealogger system on board the R/V Onnuri. A SeaBeam 2000 has 121 beams and a swath width of 92 degree with a frequency band of $12 \mathrm{kHz}$. The propagation velocity of underwater acoustics is affected by water temperature, and the physical property of the medium that are important collection variables for the calculation of slope distance (Medwin and Clay 1997; Jones 1999). Sound velocity profiles were obtained for water depth using XBT (Expandable Bathy-thermograph) and CTD (Conductivity, Temperature, Dissolved Oxygen) data. Recorded multibeam swath data was processed using a MB-System software which was built on the GMT utilities. To remove noises, a built-in module in the MB-system 'mbedit' was applied to each ping.

Based on multibeam echo sounding data, slope analysis of the seafloor was carried out using a Spatial Analyst and 3D Analyst module of ARC/INFO to find out the relationship between slope and nodule abundance. Each sample point has an X, Y coordinate and Z-Value as a bathymetry. The study area shows slopes dominantly less than $5^{\circ}$. The slope was divided into a total of 23 groups: $0.5^{\circ}$ interval for the range of $0^{\circ}$ to $5^{\circ}, 1^{\circ}$ interval for the range of $5^{\circ}$ to $10^{\circ}, 2^{\circ}$ interval for the range of $10^{\circ}$ to $20^{\circ}, 5^{\circ}$ interval for the range of $20^{\circ}$ to $30^{\circ}$, and one group for the range of $30^{\circ}$ to $90^{\circ}$.

Water depth analysis was carried out to determine the relationship between water depth and nodule abundance. It is classified into 21 groups at a $100 \mathrm{~m}$ depth interval.

Topography analysis was carried out to establish the relationship between the topography of the seafloor and nodule abundance. It is classified into 5 groups such as seamount, hill crest, hill slant, hill base or plain, and seafloor basin or valley. It is difficult to classify topography, because the criterion for topographic classification is not defined clearly in the study area, but the following definitions were used for the classification of topography in this study. A mountain on the ocean floor which does not break the water surface was classified into a seamount, while a conically shaped mountain less than $1,000 \mathrm{~m}$ in height as an isolated steep-sided hill (Allaby and Allaby 1999). Abyssal hills are defined as relatively small topographic features developed in a predominantly flat, deep-ocean floor, commonly 50-250 $\mathrm{m}$ in height and a few $\mathrm{km}$ in width. They are the most common topographic features of the Pacific Ocean floor at depths of 3,000-6,000 m. The 
basin or seafloor basin represents a major relief depression, influenced by the structure, or formed by erosion. The plain is defined as a flat area, developed at a low elevation. It is an extensive region of comparatively smooth and level ground with gently undulating land lacking prominent surface irregularities. The covering sediments are usually thin layers of a pelagic ooze or distal turbidite. The valley is defined as a wide, low relief depression of the ocean floor with gently sloping sides.

\section{Subbottom profile data}

A high frequency subbottom profile that penetrates up to several tens of meters below the seafloor is a useful tool in understanding the characteristics of sea bottom sediments without in-situ sampling, because characteristics of reflected echoes are controlled by texture and geometry of sediments (Damuth and Hayes 1977; Damuth 1978; Pratson and Laine 1989; Kuhn and Weber 1993; Chough et al. 1997; Dowdeswell et al. 1997; Taylor et al. 2000). Sediment layers are essential for nodule's growth by diagenesis and benthic activity (von Stackelberg and Beiersdorf 1991; Jung and Lee 1999). The thickness of the sediment layer is related to the sedimentation rate, which in turn has a strong effect on the growth of manganese nodules. Generally, abundance of manganese nodules is high in a sedimentstarved area and low where surface productivity and the carbonate sedimentation rate are high (Skornyakova \& Murdmaa 1992). Thus, the formation of manganese nodules are dependent on the characteristics of the uppermost sediment layer, and the distribution of manganese nodules could be inferred from the nature of uppermost sediment layer (Usui and Tanahashi 1992; Jeong et al. 1994, 1996).

Subbottom profiles are classified into three types of acoustic layers: an acoustically transparent layer (TL) lacking an internal reflection layer, an acoustically opaque layer $(\mathrm{OL})$ produced from an acoustically perfect reflective layer, and an acoustically stratified layer (SL) with densely internal reflection layers (Kim et al. 1998). The acoustically transparent layer is from the uppermost sedimentary layer. The transparent layer is generally thick on the seafloor basin and valley, thin or non-existent in other areas. The abundance of manganese nodules is known to have an inverse relationship on the thickness on the acoustically transparent uppermost sedimentary layer in the Central Pacific and C-C zone (Usui and Tanahashi 1986; Jeong et al. 1994, 1996). An inverse relationship of nodule abundance to the thickness of uppermost sediment layer indicates that erosional processes facilitate nodule generation by bottom currents (Glasby 1978; Mizuno et al. 1980; Usui et al.
1987). The sediment composition of radiolarian ooze and clay, with high porosity and similar density is responsible for the acoustic transparency of the uppermost sediment layer.

The acoustically transparent layer, obtained by $3.5 \mathrm{kHz}$ high-resolution seismic profiler, is useful for the study of manganese nodule distribution, subbottom sediment structure and distribution, and sedimentary sequence distribution to tens of meters (Usui and Tanahashi 1986; Usui et al., 1987). High-resolution ( $3.5 \mathrm{kHz}$ ) subbottom profiles were obtained at the manganese nodules' sampling sites using a Bathy-2000P using FM or chirp mode source. The subbottom profile data were obtained where FFGs were deployed and along the shifting line between these stations. Data in the sampling stations generally have better qualities than those on the shifting line, because the research vessel was moving slowly at these stations to recover FFG samples. In this study, the subbottom profile data was used for analysis of transparent layer distribution using the kriging method. The acoustic characteristics of near-surface sediments from a high-resolution subbottom profile on the sampling sites were analyzed to calculate the abundance of manganese nodules, especially in terms of the thickness of the transparent upper layers. Transparent layer thickness ranges from $0 \mathrm{~m}$ to $90 \mathrm{~m}$.

\section{Calculation relationships between manganese nodule abundance and geologic/topographic factors}

The database for factors related to manganese nodule development, such as manganese nodule abundance, metal grade from geochemical analysis, geomorphic characteristics, and acoustic characteristics, was constructed using GIS. Using the sampling data of manganese nodule abundance and the constructed spatial database, an analysis method was applied. A probability analysis was performed and the rating of each factor was calculated.

The calculated and extracted factors were converted into a $100 \times 100 \mathrm{~m}$ grid using the GIS, and then converted into Data Base File (DBF) data in order to determine statistical relationships between the sampling abundance and each factor, such as the copper and nickel grade, slope, water depth, topography, and transparent layer thickness. The rating was calculated by analyzing the correlation between nodule abundance and the metal grade, slope, water depth, topography, and acoustic characteristics of the subbottom such as that given in equation (3):

$$
R=\frac{\Sigma w \times N p}{N t}
$$


where $R$ is the rating of each class, $w$ is the weight of the sampling abundance, $N_{p}$ is the number of the sampling point and $N_{t}$ is the total number of the sampling points

\section{Analytical results}

Relationship between copper grade and manganese nodule abundance

In the B2 block, the copper grade ranged from 2.3 to $174.3 \mathrm{~g} / \mathrm{m}^{2}$ units with an average of $63.5 \pm 28.3 \mathrm{~g} / \mathrm{m}^{2}$ (average \pm 1 s.d.) (Fig. 2). The area containing the nodule with the copper grade of over $50 \mathrm{~g} / \mathrm{m}^{2}$ covered $65 \%$ of the

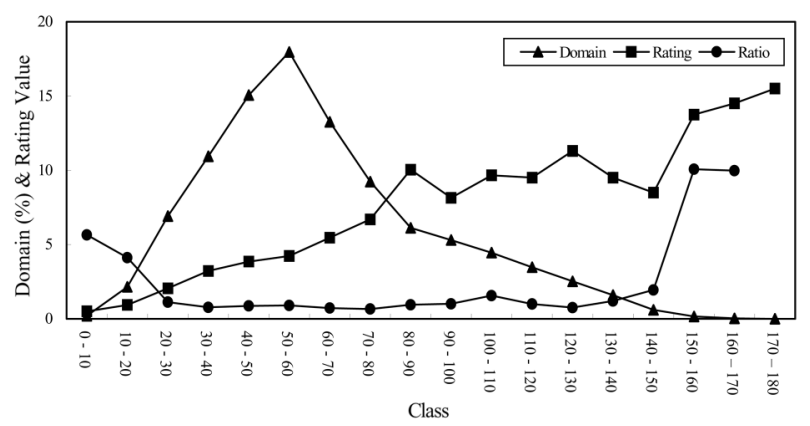

Fig. 2. The relationship between 1) domain and copper grade, 2) rating and copper grade for block B2.
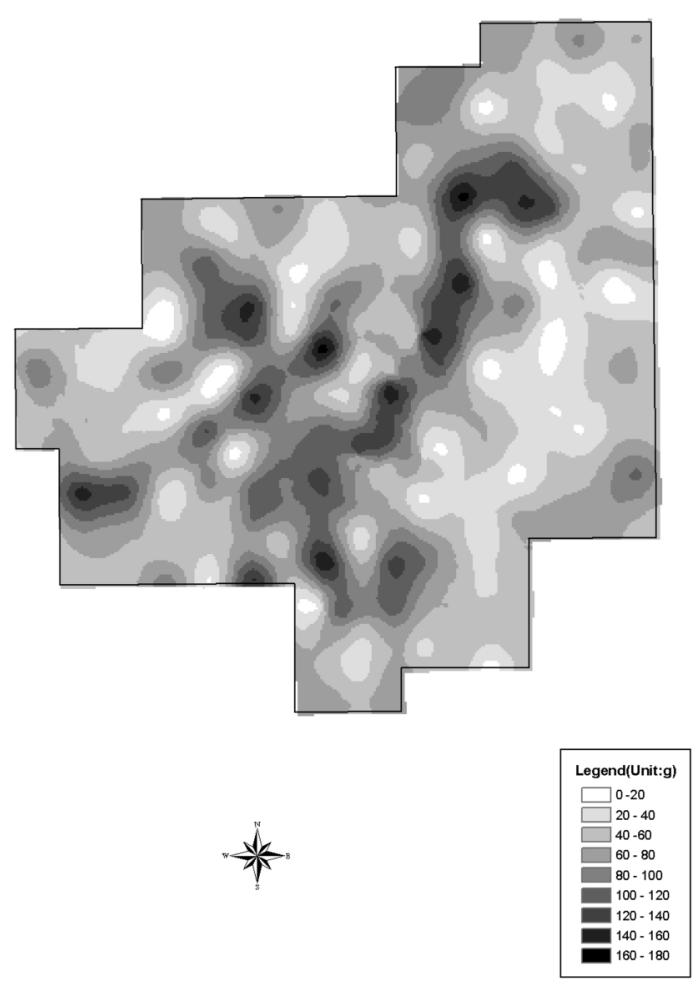

Fig. 3. The distribution map of copper grade for block B2. block. Overall, the greater the copper grade, the higher the rating. The areas of greatest abundance had a NE-SW distribution, with the most impoverished area surrounding this region of high abundance (Fig. 3).

In the $\mathrm{C} 1$ block, the copper grade ranged from 0 to $148.9 \mathrm{~g} / \mathrm{m}^{2}$ unit with an average of $42.1 \pm 22.8 \mathrm{~g} / \mathrm{m}^{2}$ (Fig. 4). The area containing the nodule with the copper grade of over $50 \mathrm{~g} / \mathrm{m}^{2}$ covered $29 \%$ of the block. The reduction of $\mathrm{R}^{2}$ arises from an anomalous datum that exists in class 80-90. Overall, the greater the copper grade, the higher the rating. There were rich circular areas in the southwest, northwest, and east, with an impoverished zone lying along the NW-SE axis (Fig. 5).

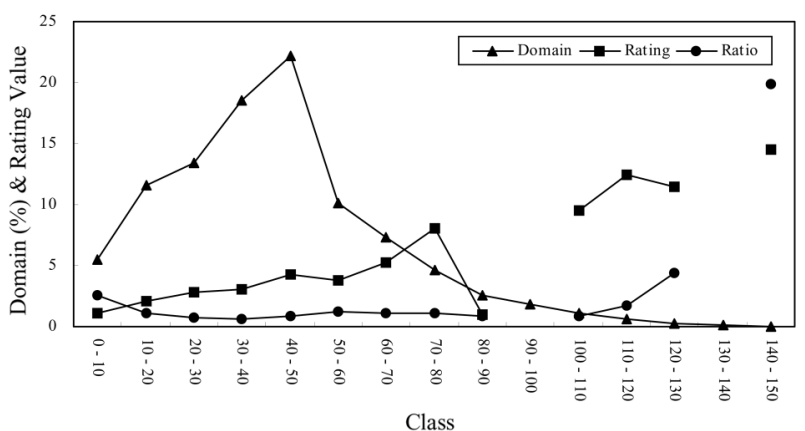

Fig. 4. The relationship between 1) domain and copper grade, 2) rating and copper grade for block $\mathrm{C} 1$.
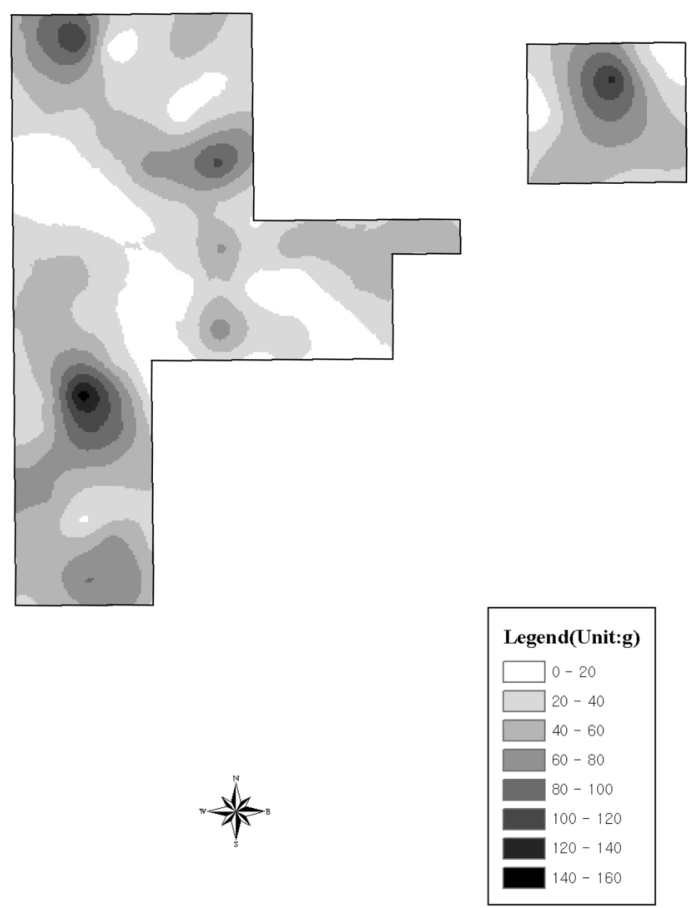

Fig. 5. The distribution map of copper grade for block C1. 
Relationship between nickel grade and manganese nodule abundance

The distribution pattern of nickel grade is similar to that of copper grade. In the B2 block, the nickel grade ranged from 2.9 to $226.8 \mathrm{~g} / \mathrm{m}^{2}$ unit with an average of $70.0 \pm 32.1$ $\mathrm{g} / \mathrm{m}^{2}$ (Fig. 6). The area containing the nodule with the nickel grade of over $60 \mathrm{~g} / \mathrm{m}^{2}$ covered $55 \%$ of the block. Over $63 \%$ of the area was between 30 and $80 \mathrm{~g} / \mathrm{m}^{2}$. Sampling stations were distributed over $50 \%$ of the block at ranges from 30 to $80 \mathrm{~g} / \mathrm{m}^{2}$. In general, the greater the nickel grade, the higher the rating. There was a rich area

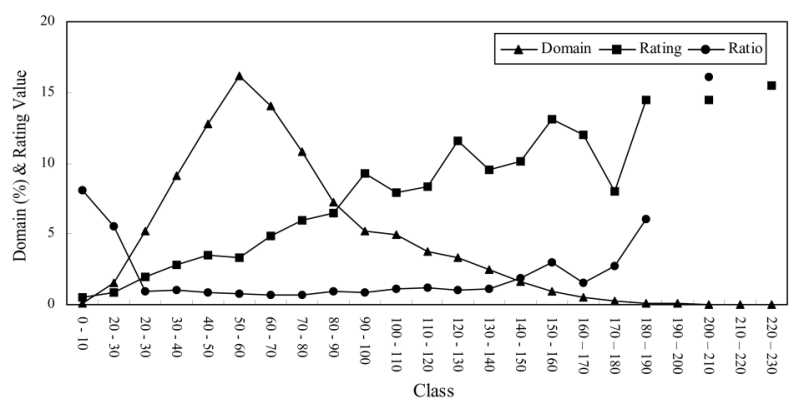

Fig. 6. The relationship between 1) domain and nickel grade, 2) rating and nickel grade for block $B 2$.
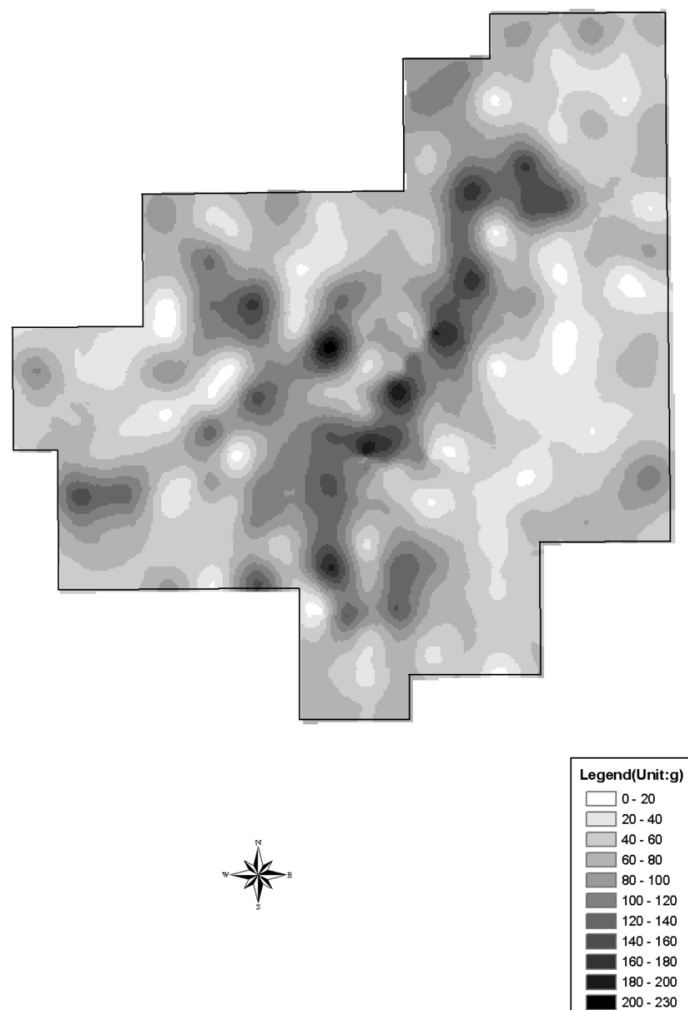

Fig. 7. The distribution map of nickel grade for block B2. along the NE-SW axis, with a second perpendicular to one end of the first area (Fig. 7). The remainder of the block had low nickel grade. This well matched the distribution of the copper grade.

In block $\mathrm{C} 1$, the nickel grade ranged from 0 to $165.4 \mathrm{~g} / \mathrm{m}^{2}$ unit with an average of $44.0 \pm 25.3 \mathrm{~g} / \mathrm{m}^{2}$ (Fig. 8). The area containing the nodule with the nickel grade of over $60 \mathrm{~g} / \mathrm{m}^{2}$ covered $21 \%$ of the block. Over $73 \%$ of the area was between 10 and $60 \mathrm{~g} / \mathrm{m}^{2}$. Sampling stations were distributed over $86 \%$ of the block at ranges of 0 to $70 \mathrm{~g} / \mathrm{m}^{2}$. In general, the greater the nickel grade, the higher the rating. The distribution pattern was similar to that of copper, with a low grade throughout the block (Fig. 9).

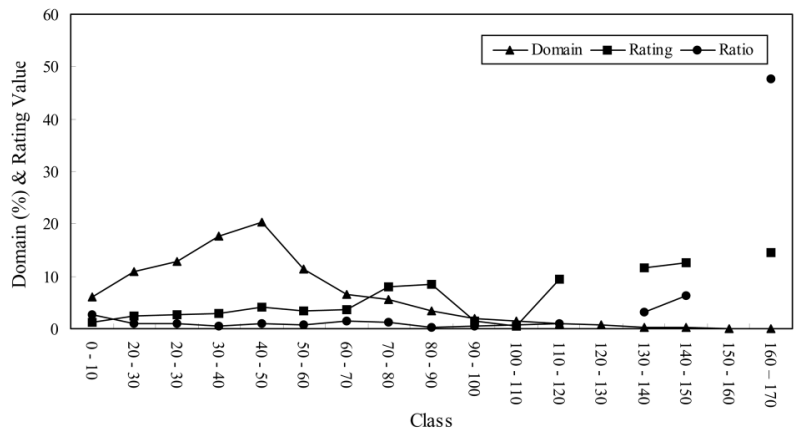

Fig. 8. The relationship between 1) domain and nickel grade, 2) rating and nickel grade for block $\mathrm{C1}$.
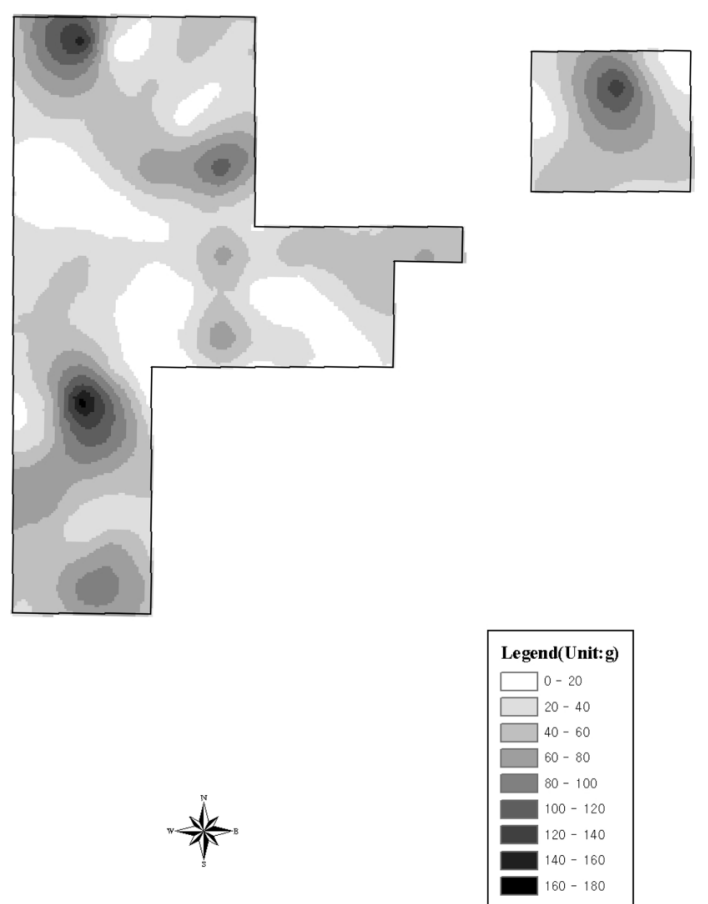

Fig. 9. The distribution map of nickel grade for block C1. 


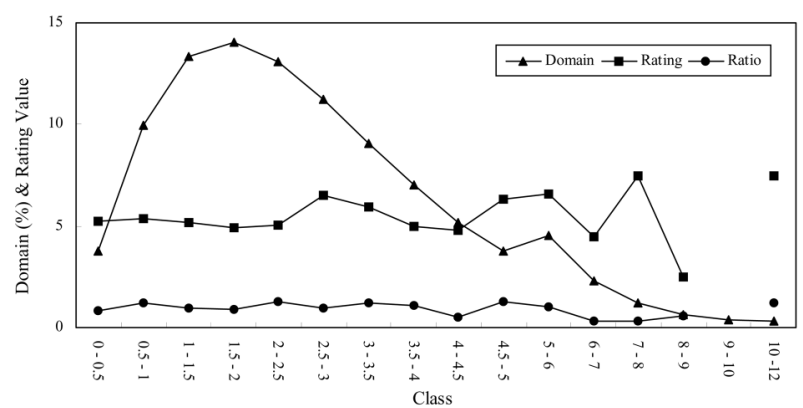

Fig. 10. The relationship between 1) domain and slope, 2) rating and slope for block $B 2$.

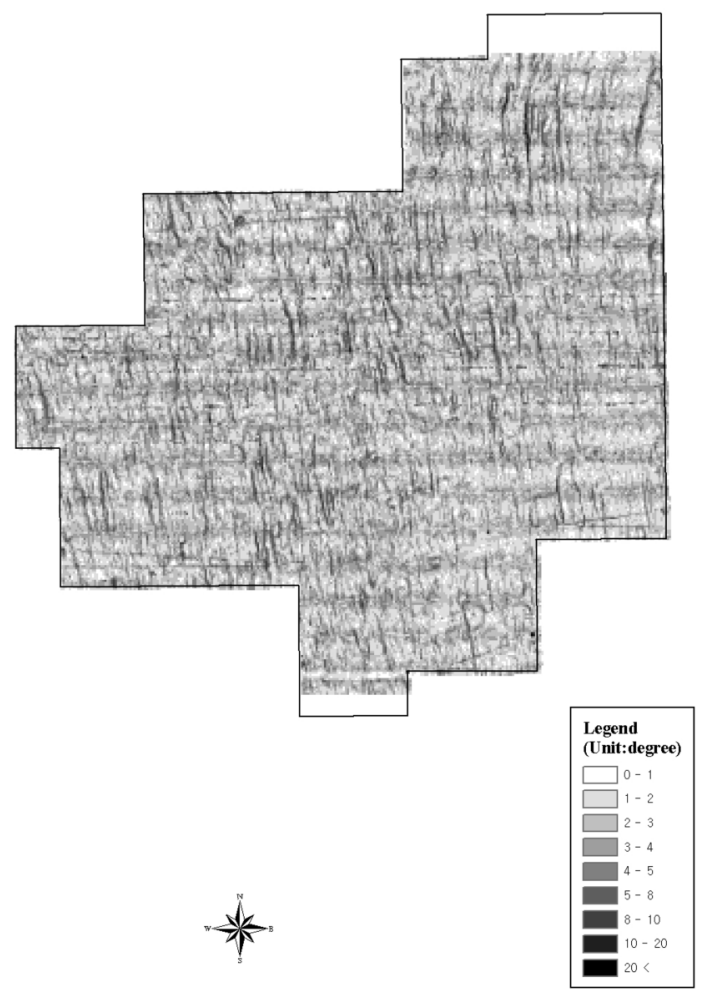

Fig. 11. Slope map for block B2.

Relationship between slope and manganese nodule abundance

In general, the slopes were less than $3^{\circ}$, excluding seamounts and cliff areas. It was difficult to make a precise correlation between seafloor topography and nodule abundance. In the B2 block, Slopes ranged from 0 to $66^{\circ}$ with an average of $2.7 \pm 1.8^{\circ}$ and were classified into 23 groups (Fig. 10). The area occupied by slopes below $5^{\circ}$ was $90 \%$. Sampling stations were distributed such that $75 \%$ lay in areas with slopes from 0.5 to $3.5^{\circ}$. Ratings were highest in class $2.5-3.5^{\circ}$. In general, block B2 was flat with a noticeable slope was pronounced only in the valley region (Fig. 11).

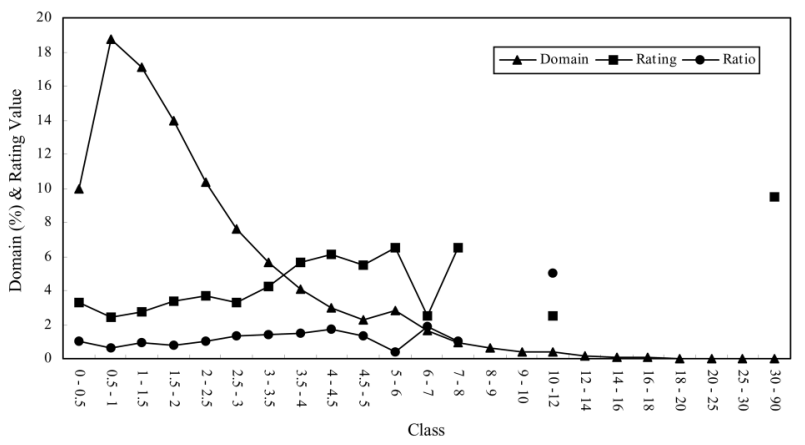

Fig. 12. The relationship between 1) domain and slope, 2) rating and slope for block $\mathrm{C} 1$.
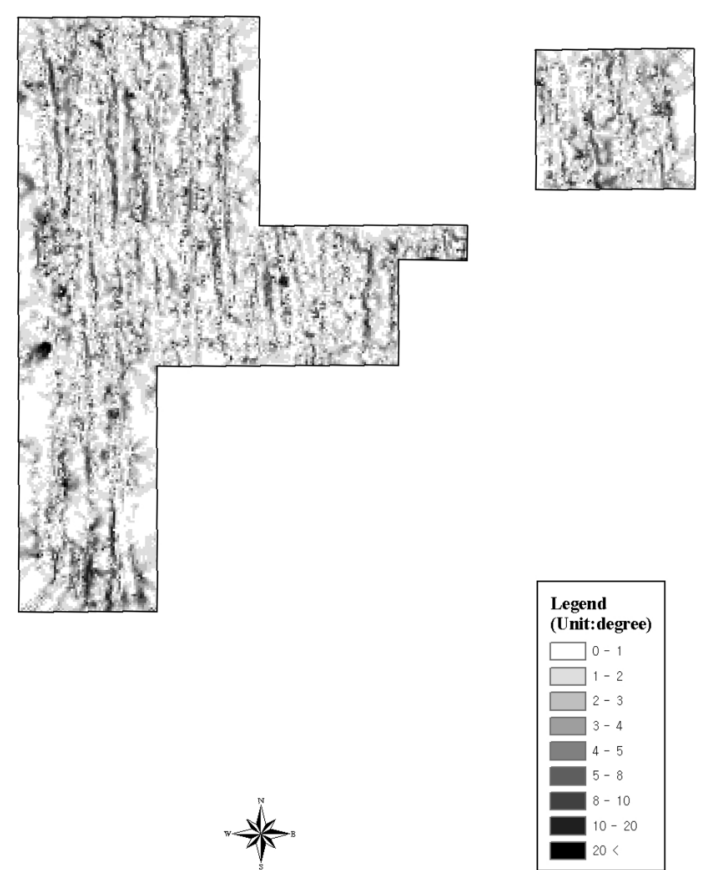

Fig. 13. Slope map for block C1.

In block $\mathrm{C} 1$, slopes ranged from 0 to $60^{\circ}$ with an average of $2.2 \pm 2.0^{\circ}$ and were classified into 23 groups (Fig. 12). 93\% of the area was occupied by slopes below $5^{\circ}$. Sampling stations were distributed such that $78 \%$ lay in areas with slopes from 0 to $3^{\circ}$. Ratings were highest in class $3.5-6^{\circ}$. In general, the greater the slope, the lower the rating. Block $\mathrm{C} 1$ was flat with a marked slope which was pronounced only in the valley (Fig. 13).

\section{Relationship between water depth and manganese nodule abundance}

The rating decreased with increasing water depth in the study area. In block B2, the water depth ranged from 4,553 to $5,628 \mathrm{~m}$ with an average of 4,973 $\pm 100.8 \mathrm{~m}$. It was classified into 11 groups (Fig. 14). Areas with depths 


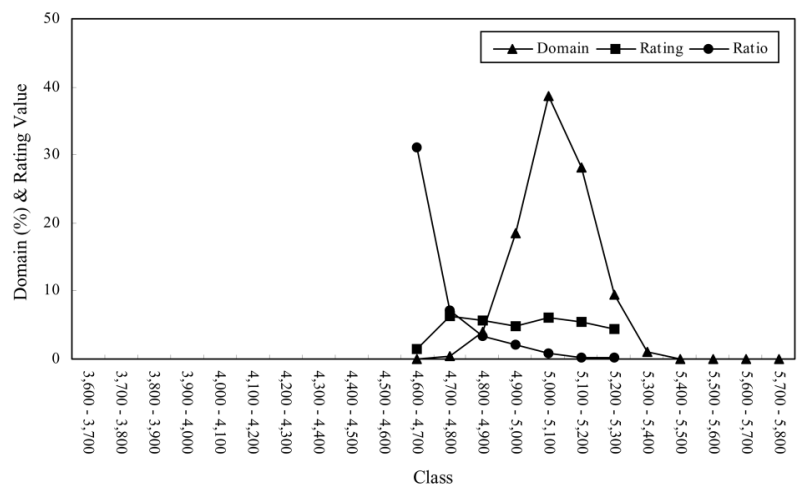

Fig. 14. The relationship between 1) domain and water depth, 2) rating and water depth for block B2.

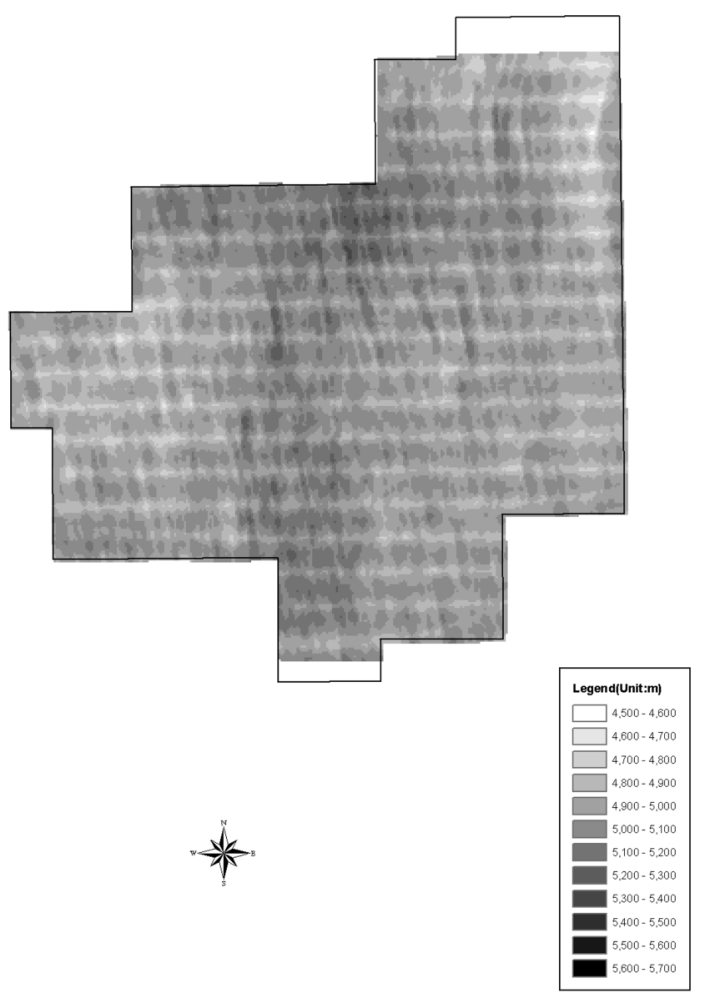

Fig. 15. Bathymetric map for block $B 2$.

of 4,900 to $5,300 \mathrm{~m}$ covered $94 \%$ of the block surface (Fig. 15). Most of the sampling stations showed water depths between 4,800 and 5,100 m. Geomorphologically, the eastern and western parts of this block consisted of high topographic, with lower topographic occupying the central part, and a pronounced geomorphic trend along the NNW-SSE axis. Ratings were highest from 5,000 to 5,200 $\mathrm{m}$ and lowest from 4,900 to $5,000 \mathrm{~m}$. In general, the deeper the water depth, the lower the rating.

In block $\mathrm{C} 1$, the water depth ranged from 4,394 to $5,666 \mathrm{~m}$ with an average of $4,825 \pm 81.48 \mathrm{~m}$. It was

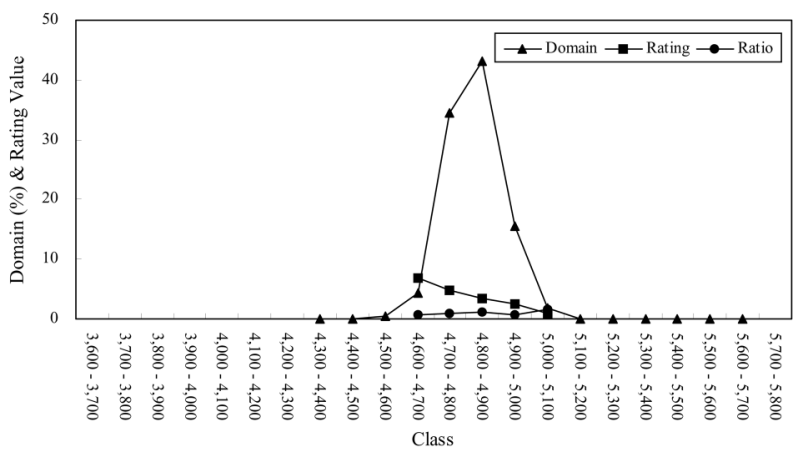

Fig. 16. The relationship between 1) domain and water depth, 2) rating and water depth for block $\mathrm{C} 1$.
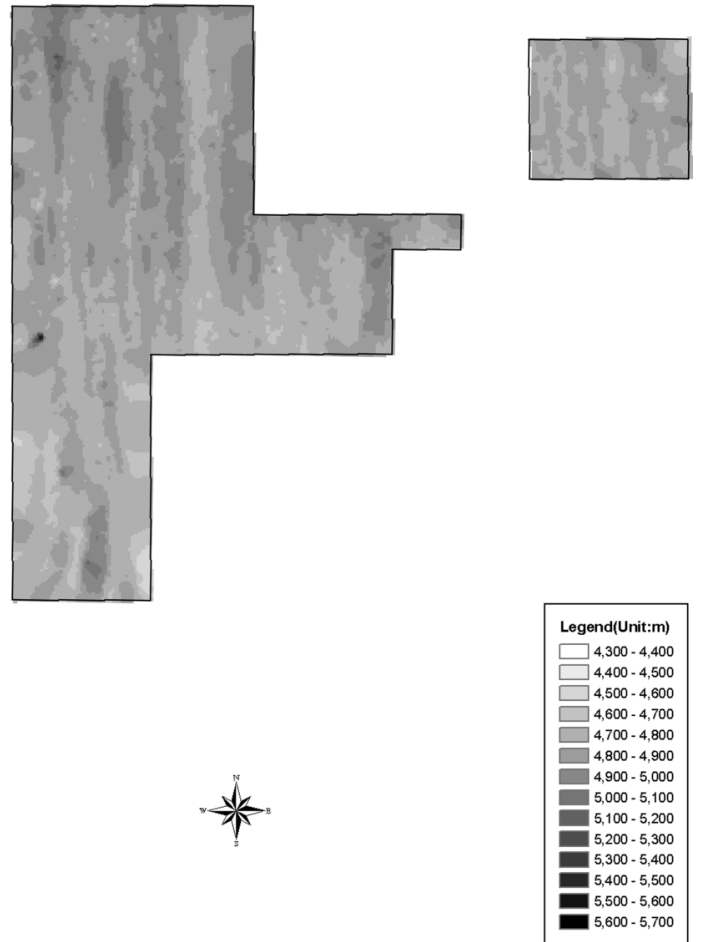

Fig. 17. Bathymetric map for block $\mathrm{C} 1$.

classified into 14 groups (Fig. 16). Areas with depths of 4,700 to 5,700 m covered $93 \%$ of the block surface (Fig. 17). Most of the sampling stations showed water depths between 4,700 and 5,000 m. The topography deepened toward the north in the western part of the block, resulting in a geomorphic trend in a NNW-SSE direction. The rating was highest from 4,600 to $4,800 \mathrm{~m}$. In general, the deeper the water depth, the lower the rating.

\section{Relationship between topography and manganese nodule abundance}

The topography was classified into five groups: seamount, hill crest, hill slant, hill base or plain, and seafloor basin or 
valley. The ratings proved lowest for seamount and hill crest. As with water depth, the ratings generally decreased toward the seafloor basin.

In block B2, the topography was classified into five groups: seamount, hill crest, hill slant, plain, and seafloor basin or valley (Fig. 18). In this block, seamount areas were defined as having high topographic with a water depth of 4,553 to $4,700 \mathrm{~m}$. Hill crests were defined as topographically high with a water depth of 4,700-4,800 m. The part of the hill that lies between 4,800-5,000 m was defined as hill slants, and between 5,000-5,100 $\mathrm{m}$ in depth at the hill base. The area with water depths of 5,100$5,628 \mathrm{~m}$ was defined as a valley. Ratings proved high on plains and lowest for hill slants and seafloor basins. Hill

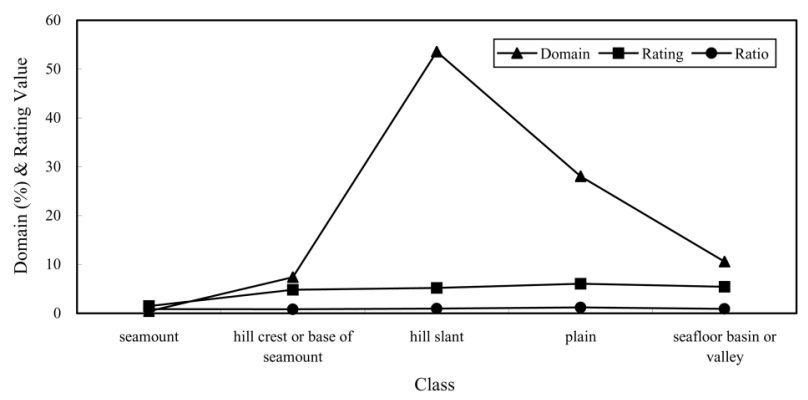

Fig. 18. The relationship between 1) domain and topography, 2) rating and topography for block B2.

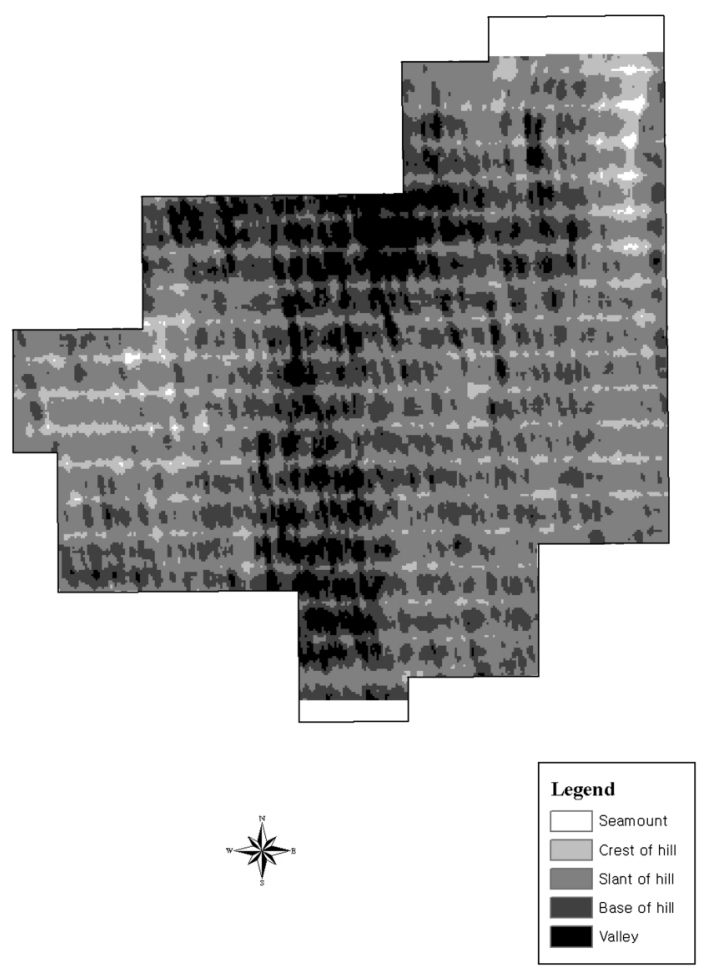

Fig. 19. Topography map for block B2. slants, plains, hill crests and seafloor basins or valleys occupied $82 \%, 7.4 \%, 10.6 \%$ of block B2, respectively (Fig. 19). More than $85 \%$ of the sampling stations were located on seamounts, hill slants and plains.

In block $\mathrm{C} 1$, the topography was classified into five groups: seamount, hill crest, hill slant, hill base or plain, and valley (Fig. 20). In this block, seamount areas were defined as topographic high with water depths of 4,394 to 4,500 m. Hill crests were defined as topographic high with water depths of 4,500-4,730 m. The part of the hill that lies between 4,730-4,900 $\mathrm{m}$ was defined as hill slants, and between 4,900-5,000 $\mathrm{m}$ in depth as the hill base. The area with water depths of 5,000-5,666 m were defined as valleys. Hill slants, hill crests and hill bases occupied $72 \%$, and $26 \%$ of block C1, respectively (Fig. 21). More

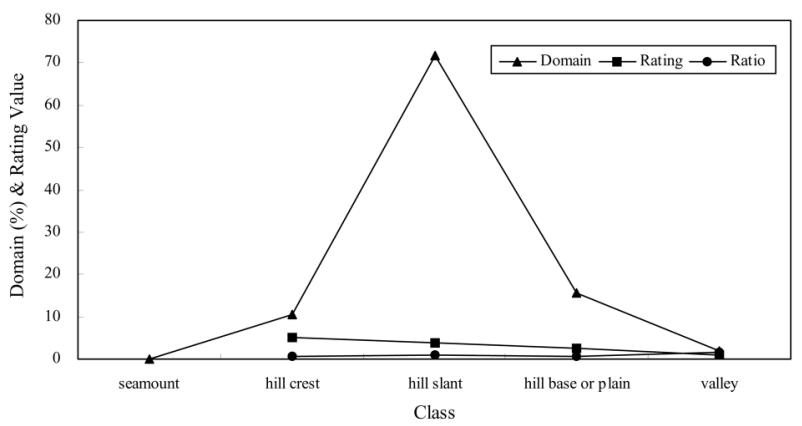

Fig. 20. The relationship between 1) domain and topography, 2) rating and topography for block $\mathrm{C} 1$.

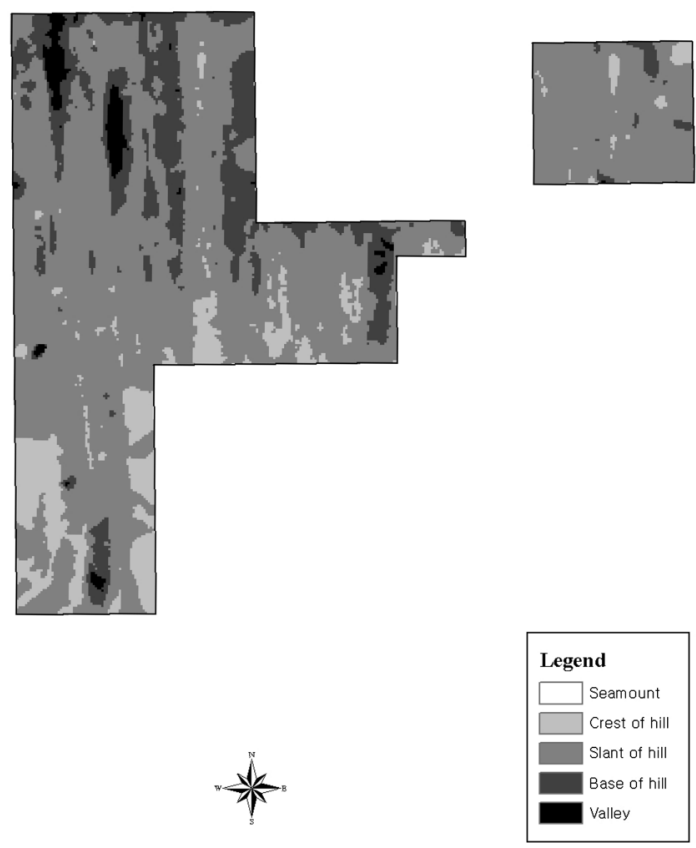

Fig. 21. Topography map for block C1. 
than $89 \%$ of the sampling stations were located on hill slants and hill bases.

\section{Relationship between transparent layer thickness and manganese nodule abundance}

There was an inverse relationship between manganese nodule abundance and the thickness of the upper transparent layer in the study area. Block B2 was not included in the analysis, because subbottom profile data for block B2 was not acquired.

In block $\mathrm{C} 1$, the transparent layer thickness ranged from 0 to $69 \mathrm{~m}$ with an average of $28.2 \pm 8.2 \mathrm{~g} / \mathrm{m}^{2}$ (Fig. 22). The area with an upper transparent layer thickness of $15-40 \mathrm{~m}$ covered $80 \%$ of block $\mathrm{C} 1$ (Fig. 23). There was a poor correlation between the thickness of this transparent layer

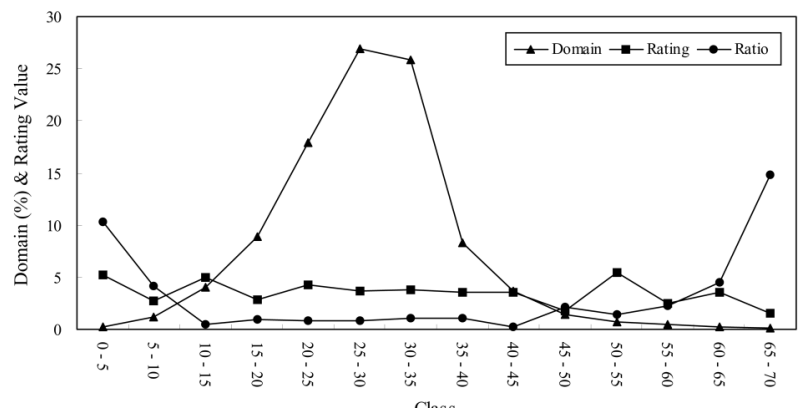

Fig. 22. The relationship between 1) domain and transparent layer thickness, 2) rating and transparent layer thickness for block $\mathrm{C} 1$.
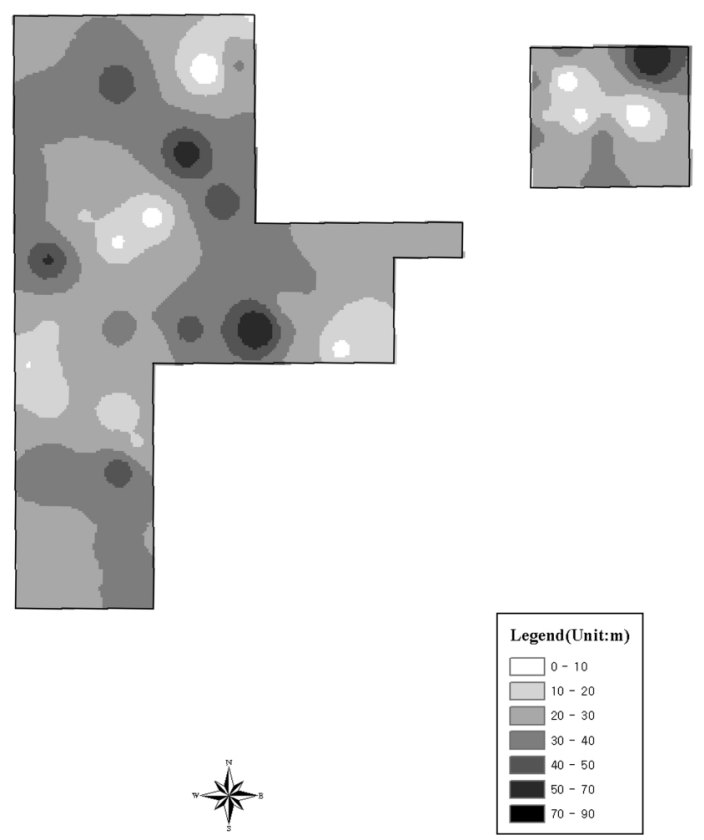

Fig. 23. Transparent layer thickness map for block $\mathrm{C} 1$. and nodule abundance. A thick transparent layer followed a NW-SE trend in the west.

\section{Discussion and conclusion}

Geological and geophysical factors for manganese nodules and seabeds containing them, such as nodule abundance, metal grade, seafloor topography, and acoustic characteristics, give a general idea of finding potential economic nodule deposits. In this study, the spatial relationships and contrast values between nodule abundance and each factor affecting abundance were assessed by combining GIS with probability methods. Using GIS, it is possible to analyze a large amount of data efficiently, and to maximize the practical application, to increase specialization, and to enhance the accuracy of the analyses.

The greater the copper and nickel grade, the higher the rating. The distribution pattern of nickel grade is similar to that of copper grade. The copper and nickel grade is highest in block B2. The slopes are generally less than $3^{\circ}$, excluding seamounts and cliff areas. There is no increment in the rating with increasing slope. The rating is highest for slopes between 2.5 and $3.5^{\circ}$ in block B2 and between 3 and $6^{\circ}$ in block C1. It is difficult to classify topography, because of the criterion for topographic classification is not defined clearly in the study area. The topography is classified into five groups: seamount, hill crest, hill slant, hill base or plain, and seafloor basin or valley. The ratings prove lowest for seamount and hill crest. It is difficult to make a precise correlation between seafloor topography and nodule abundance. But as with water depth, the ratings generally decrease toward the seafloor basin in the study area. Jeong (1993) proposed that there appeared to be a weak counter-correlation between nodule abundance and water depth in the western part of C-C zone (old Korea Deep Ocean Study area). But as the results of study indicate the rating decreases with increasing water depth in the study area. There was a poor relationship between manganese nodule abundance and the thickness of the upper transparent layer in block $\mathrm{C} 1$. And block B2 was not included in the analysis because subbottom profile data for block B2 was not acquired.

We could obtain basic information about the seafloor surface sediment characteristics by side-scan sonar data. Therefore side-scan sonar (MR1) data was used in this analysis to provide the classifications shown on the maps. However, the results do not fit well, because most of the data is concentrated in one class. In future work, high quality side-scan sonar data is needed to provide a clear 
correlation between intensity and nodule abundance.

\section{Acknowledgements}

I would like to thank Drs. Chan-Young Park and Saro Lee for their helpful and constructive comments. This work was supported by "The development of deep seabed mineral resources (PM26801 and PM26802)" and "The database construction for seafloor image data by using GIS and the investigation for data analysis methods (PE89500)".

\section{References}

Allaby, A. and M. Allaby. 1999. A dictionary of earth sciences. Oxford University Press. 1999 p.

Archer, A.A. 1976. Prospects for the exploration of manganese nodules: the main technical economic and legal problems. p. 21-38. In: Papers Presented at the I.D.O.E. Workshop, Suba, Fiji, 1-6 September, 1975. eds. by G.P. Glasby and H.R. Katz. Technical Bulletin No.2, U.N. Economic and Social Commission for Asia and the Pacific, CCOP/ SOPAC.

Bernhard, H. and H.E. Blissenbach. 1988. Economic importance. p. 4-9. In : The Manganese nodule belt of the Pacific Ocean. eds. by P. Halbach, G. Friedrich, and U. von Stackelberg. Ferdinand Enke Verlag, Stuttgart.

Chough, S.K., S.H. Lee, J.W. Kim, S.C. Park, D.G. Yoo, H.S. Han, S.H. Yoon, S.B. Oh, Y.B. Kim, and G.G. Back. 1997. Chirp (2-7 kHz) echo characters in the Ulleung Basin. Geosci. J., 1, 143-153.

Damuth, J.E. 1978. Echo character of the Norwegian-Greenland Sea: relationship to Quaternary sedimentation. Mar. Geol., 28, 1-36.

Damuth, J.E. and D.E. Hayes. 1977. Echo character of the east Brazilian continental margin and its relationship to sedimentary processes. Mar. Geol., 24, 73-95.

Dowdeswell, J.A., N.H. Kenyon, and J.S. Laberg. 1997. The glacier-influenced Scoresby Sund Fan, East Greenland continental margin: evidence from GLORIA and $3.5 \mathrm{kHz}$ records. Mar. Geol., 143, 207-221.

Earney, F.C.F. 1990. Marine mineral resources. Routledge, London. 387 p.

Frazer, J.Z. 1977. Manganese nodule reserves: an update estimate. Mar. Mining, 1, 103-123.

Frazer, J.Z. 1979. The reliability of available data on element concentrations in sea-floor manganese nodules. p. 21-36. In: Manganese nodules: dimensions and perspectives. D. Reidel Pub., Dordrecht.

Glasby, G.P. 1978. Deep-sea manganese nodules in the stratigraphic record: evidence from DSDP cores. Mar. Geol., 28, 51-64.

Holser, A.F. 1976. Manganese nodule resources and mine site availability (Professional staff study, ocean mining
Administration, Department of Interior, Washington, D.C.), Unpublished.

IFREMER. 1989. Evaluation et etude des moyens necessaires a lexploitation des nodules polymetalliques, Rapport final, TOME I, pp. 1/1-5/10, unpublished.

Japan International Cooperation Agency and Metal Mining Agency of Japan. 2000. Report on the cooperative study project on the deep sea mineral resources in selected offshore areas of the SOPAC region; Data analysis and digitalization between 1985 and 2000. 354 p. (unpublished)

Jeong, K.S. 1993. Sedimentary process and formation of manganese nodules in the Korea Deep Ocean Study (KODOS) area, western Clarion-Clipperton fracture zones, northeast equatorial Pacific. Ph.D. thesis, Seoul National University. Seoul, Korea.

Jeong, K.S., J.K. Kang, K.L. Lee, H.S. Jung, S.B. Chi, and S.J. Ahn. 1996. Formation and distribution of manganese nodule deposit in the northwestern margin of ClarionClipperton fracture zone, northeast equatorial Pacific. Geo-Mar. Lett., 16, 123-131.

Jeong, K.S., J.K. Kang, and S.K. Chough. 1994. Sedimentary process and manganese nodule formation in the Korea Deep Ocean Study (KODOS) area, western part of ClarionClipperton fracture zones, northeast equatorial Pacific. Mar. Geol., 122, 125-150.

Jones, E.J.W. 1999. Marine geophysics. John Wiley \& Sons. $466 \mathrm{p}$.

Jung, H.S. and C.B. Lee. 1999. Growth of diagenetic ferromanganese nodules in an oxic deep-sea sedimentary environment, NE equatorial Pacific. Mar. Geol., 157, 127-144.

Kildow, J.T., M.B. Bever, V.K. Dar, and A.E. Capstaff. 1976. Assessment of economic and regulatory conditions affecting ocean minerals resources department (Report to the Department of Interior, Massachusetts Institute of Technology, Cambridge), Unpublished.

Kim, H.S., T.G. Lee, Y.T. Ko, and K.H. Kim. 1998. Relationship between manganese nodule occurrence and the acoustically-transparent uppermost sedimentary layer in the Korea Deep Ocean Study (KODOS) 98-1 area, northeast equatorial Pacific. Ocean Res., 20(3), 275-284.

Ko, Y.T. 1997. A suitable site selection study for manganese nodules development by using GIS in northeastern pacific KODOS area. M. Sc Thesis, Yonsei University. Seoul, Korea.

Kuhn, G. and M.E. Weber. 1993. Acoustical characterization of sediments by Parasound and $3.5 \mathrm{kHz}$ systems: Related sedimentary processes on the southeastern Weddell Sea continental slope, Antarctica. Mar. Geol., 113, 201-217.

Manheim, F.T. 1978. Book review of G.P. Glasby, Marine Manganese Deposits. Geochem. Cosmochim. Acta, 42(5). $541 \mathrm{p}$.

Mckelvey, V.E., N.A. Wright, and R.W. Rowland. 1979. Manganese nodule resource in the northeastern equatorial Pacific. p. 747-762. In: Marine Geology and Oceanography of the Pacific Manganese Nodule Province. eds. 
by J.L. Bischoff and D.Z. Piper. Plenum, New York.

Medwin, H. and C.S. Clay. 1997. Fundamentals of acoustical oceanography. Academic Press. 712 p.

Mero, J.L. 1965. The mineral resources of the sea. Elsvier, Amsterdam, $312 \mathrm{p}$.

Mizuno, A., T. Miyazaki, A. Nishimura, K. Tamaki, and M. Tanahashi. 1980. Central Pacific manganese nodules, and their relation to sedimentary history. Offshore Tech. Conf., 3830, 331-340.

MOMAF. 1996. A report on 96 deep seabed mineral resources exploration. MOMAF, Seoul. 954 p.

MOMAF. 1997. A report on 97 deep seabed mineral resources exploration. MOMAF, Seoul. 843 p.

MOMAF. 1999. A report on 99 deep seabed mineral resources exploration. MOMAF, Seoul. 780 p.

OMCO. 1992. Methods for correcting nodule abundance estimates based upon free-fall grab recoveries. Exploration data transfer between Ocean Minerals Company and Korea Ocean Research and Development Institute. 450 p.

Park, C.Y. 1995. A geostatistical study on reserve estimation of manganese nodule deposits in Korea Deep Ocean Study (KODOS) area. Ph. D. Thesis, Seoul National University. Seoul, Korea. 160 p.

Pratson, L.F. and E.P. Laine. 1989. The relative importance of gravity-induced versus current-controlled sedimentation during the Quaternary along the mideast United-States outer continental margin revealed by $3.5 \mathrm{kHz}$ echo character. Mar. Geol., 89, 87-126.
Skornyakova, N.S. and I.O. Murdmaa. 1992. Local variation in distribution and composition of ferromanganese nodules in the Clarion-Clipperton nodule province. Mar. Geol., 103, 381-405.

Taylor, J., J.A. Dowdeswell, N.H. Kenyon, R.J. Whittington, T.C.E. van Veering, and J. Mienert. 2000. Morphology and Late Quaternary sedimentation on the North Faeroes slope and abyssal plain, North Atlantic. Mar. Geol., 168, $1-24$.

Usui, A., A. Nishimura, M. Tanahashi, and S. Terashima. 1987. Local variation of manganese nodule facies on small abyssal hills of the Central Pacific Basin. Mar. Geol., 74, 237-275.

Usui, A. and M. Tanahashi. 1986. Relationship between local variation of nodule facies and acoustic stratigraphy in the GH81-4 area. Geol. Surv. Japan Cruise Rept., 21, $160-170$.

Usui, A. and M. Tanahashi. 1992. Relationship between local variation of nodule facies and acoustic stratigraphy in the southern part of the Central Pacific Basin (GH824 area). Geol. Surv. Japan Cruise Rept., 22, 219-231.

von Stackelberg, U. and H. Beiersdorf. 1991. The formation of manganese nodules between the Clarion and Clipperton fracture zones southeast of Hawaii. Mar. Geol., 98, 411423. 